\title{
Repair of reinforced concrete beams in shear using composite materials PRFG subjected to cyclic loading
}

\author{
Boumaaza M ${ }^{1}$, , Bezazi A ${ }^{2}$, Bouchelaghem $\mathrm{H}^{2,3}$, Benzannache ${ }^{1}$, Amziane S ${ }^{4}$, Scarpa ${ }^{5}$ \\ 1* Laboratory of Civil Engineering \& Hydraulics (LGCH)/Guelma University, Algeria \\ 2 Laboratory of Applied Mechanics of New Materials ((LMANM)/University of Guelma, Algeria \\ 3 Department of Mechanical Engineering/University of Constantine1, Algeria \\ 4 Department of Civil Engineering, Polytech Clermont Ferrand/Blaise Pascal University, France \\ 5 Advanced Composites Center for Innovation and Science (CCCTB)/University of Bristol, UK \\ Corresponding author: messaoudabeb@yahoo.fr
}

\begin{abstract}
Nowadays, finding new approaches to attenuate the effects of the catastrophic shear failure mode for reinforced concrete beams is a major challenge. Generally the bending failure is ductile. It allows a redistribution of the stresses providing an early warning, whereas the rupture by shear is fragile and sudden which can lead to detrimental consequences for the structures. This research focuses on the repair of deep beams in reinforced concrete shear subjected to 4-point bending. After being preloaded at different levels of their ultimate loads, the beams are repaired by bonding a composite material made of an epoxy resin reinforced by glass fibers. The main objective of this study is to contribute to the mastery of a new method developed by the authors that consists by banding the cracks in critical zones in order to avoid fragile ruptures due to the shear force. This new technique led to better results in terms of mechanical properties when compared to conventional methods, notably the absence of the debonding of the composite found in the case of the repairs of the beams by bands or U-shaped composites. The feasibility, the performances and the behavior of the beams have been examined. The experimental approach adopted using this new technique has shown the influence of the type of loading on the fatigue behavior. In addition, the repair performed led to a considerable improvement in the fatigue durability of the preloaded beam.
\end{abstract}

Key words: Deep beam, Shear failure, Preloading, Composite, Repair.

\section{Introduction}

During their lifetime, concrete structures can be subjected to different types of loading and environmental conditions. Cracks produced and preload conditions are initial damage that can affect long-term structural behavior. These initial cracks and damage propagate and increase over time as a result of cyclic loading. In the case of deep bridge beams, for example, the structural elements are subjected in service to maximum values stresses of generally known but time-varying, most of which result from cyclic variations in stresses.

Generally a bridge is designed for a century, even in a regulatory way, their operating conditions turns out to change following the development not only of the size and load of vehicles but also road traffic. This leads to a reduction in their initial lifetime, sometimes causing catastrophic ruptures even when they are subjected to cyclic of modest maximum value stresses. The phenomenon involved in this is fatigue damage. It is characterized by irreversible deformations in the form of cracks that develop slowly over time without macroscopic signs. By accumulating, these can lead to a catastrophic rupture.

Indeed, the literature review shows clearly that experimental research and analytical studies on the fatigue behavior of reinforced concrete (RC) beams reinforced or repaired with FRP are very limited. The majority of these studies relate to flexural reinforcement, while very few studies have been carried out on shear reinforcement (deep beams). 
Meier et al. (1992) tested two RC beams reinforced with a hybrid glass/carbon composite. Bames and Mays (1999) conducted an experimental program to study the flexural behavior of reinforced RC beams using FRP under fatigue stress. The reinforcement used is a unidirectional composite fabric based on carbon fibers (CFRP) bonded to the underside of the beam (tensile zone), which leads to the conclusion that the internal reinforcement rate affects the failure mode. Shahawy and Beitelman (1999) tested six beams of T shape under cyclic fatigue with a loading level between 0 to $25 \%$ of the ultimate load.

Papakonstantinou et al. (2001) also conducted fatigue tests in 4-point bending at a frequency of 2 or $3 \mathrm{~Hz}$ on 14 reinforced RC, eight reinforced with glass fiber (GFRP), and six non-reinforced with different fatigue loading levels. On the one hand, they found that the fatigue failure of the reinforced beams is caused by the fatigue failure of the tensile steel armature reinforcements after their plastification and, on the other hand, the use of the FRP increases the lifetime of the beams loaded at cyclic loading.

Masoud et al. (2001) also performed fatigue tests under 4-point bending with a frequency of 3 $\mathrm{Hz}$ on $\mathrm{RC}$ beams, whose tensile steel armature are corroded, reinforced with a carbon fabric. The loading level is between $10 \%$ and $80 \%$ of the ultimate strength of unreinforced RC beams. The fatigue failure of reinforced beams is caused by the fatigue of the tensile armatures similarly to Shahawy and Beitelman (1999).

In addition, some studies have also investigated a structural elements preloaded, reinforcement with composite materials in particular (Arduini, 1997; Choi et al.; De Lorenzis and Teng, 2007; Boussaha, 2008; Kreit, 2011; Dong, 2013 and Teo, 2017). The problems of premature failure associated with the complexity and incomprehension of the shear behavior of RC beams, under cyclic fatigue loading (loading/unloading) were the aim of this study.

The main objective of this study is to elucidate, using an experimental investigations, the fatigue behavior of deep beams repaired by FRP using a new technique. This technique was developed recently by the authors Boumaaza et al. (2017) for static tests (non-cyclic). The deep beam, used in the present work, is tested under 4-point bending assuming that the shear failure mode is predominant, with cyclic loading. For this purpose, a beam is preloaded at $80 \%$ of its ultimate load and then it has repaired by composite materials using the new technique SCR. After at list 15 days, resin polymerization time, the beam is cycled 19 times at $65 \%$ of its ultimate load.

\section{Experimental protocol}

The aim of the experimental part is to investigate the fatigue behavior of the RC deep beams under cyclic loading (load/unload), repaired by glass fiber composites (GFRP) using the SCR technique. The concrete beams were designed in accordance with ASTM C78-00, armed with two HA8 in tensile zone and two HA6 in compressed zone, and 6 frames used as transverse reinforcements spaced of $110 \mathrm{~mm}$. Fig. 1 shows the detail of the reinforcement in steel armatures of the beams. After at least 28 days, the manufactured beam is preloaded at $60 \%$ of its ultimate load.

The beam is repaired using the SCR technique which requires the preliminary work as follows:

- Drilling the beam on each side at the vicinity of the diagonal cracks of the concrete by passing through it (Figure 2a);

- Before the glass fabric was inserted, a repair was carried out using the mortar Fig. 2(b);

- The positions of the grooves, having $25 \mathrm{~mm}$ wide and $3 \mathrm{~mm}$ depth, were traced on the surface of the beam (Figure 2c). Then the grooves are subsequently cleaned of dust and concrete debris; 


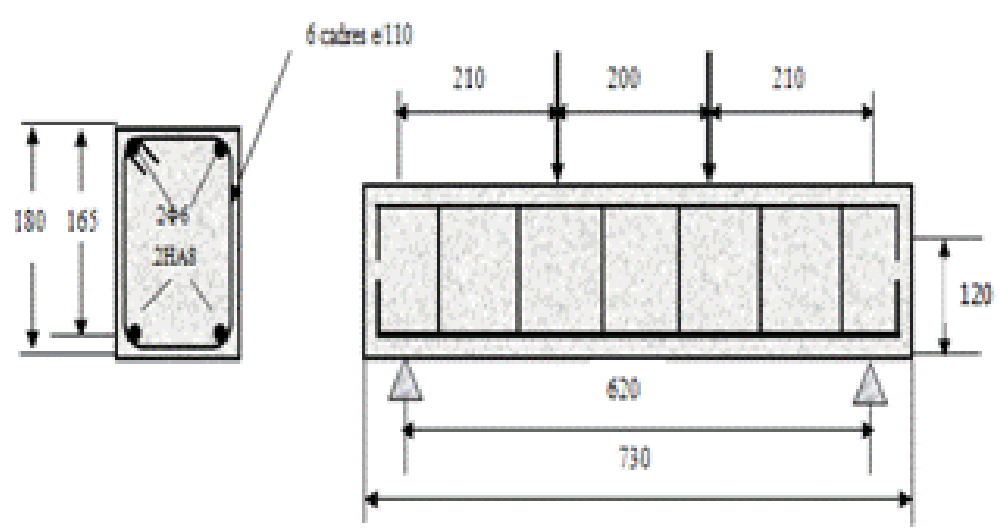

Fig 1. Schematic layout of the specimen and steel reinforcement in accordance with ASTM 78-00.

- The unidirectional of $600 \mathrm{~g} / \mathrm{m}^{2}$ surface density fabric is cut in pieces having a size of $1500 \times 25 \mathrm{~mm}$ and $1000 \times 25 \mathrm{~mm}$. Then the fabric, previously impregnated with the epoxy resin, is inserted into the grooves.

SCR repair involves introducing composite bands into holes in the shear zone in order to band the diagonal cracks (Figure $2 \mathrm{~d}$ ).
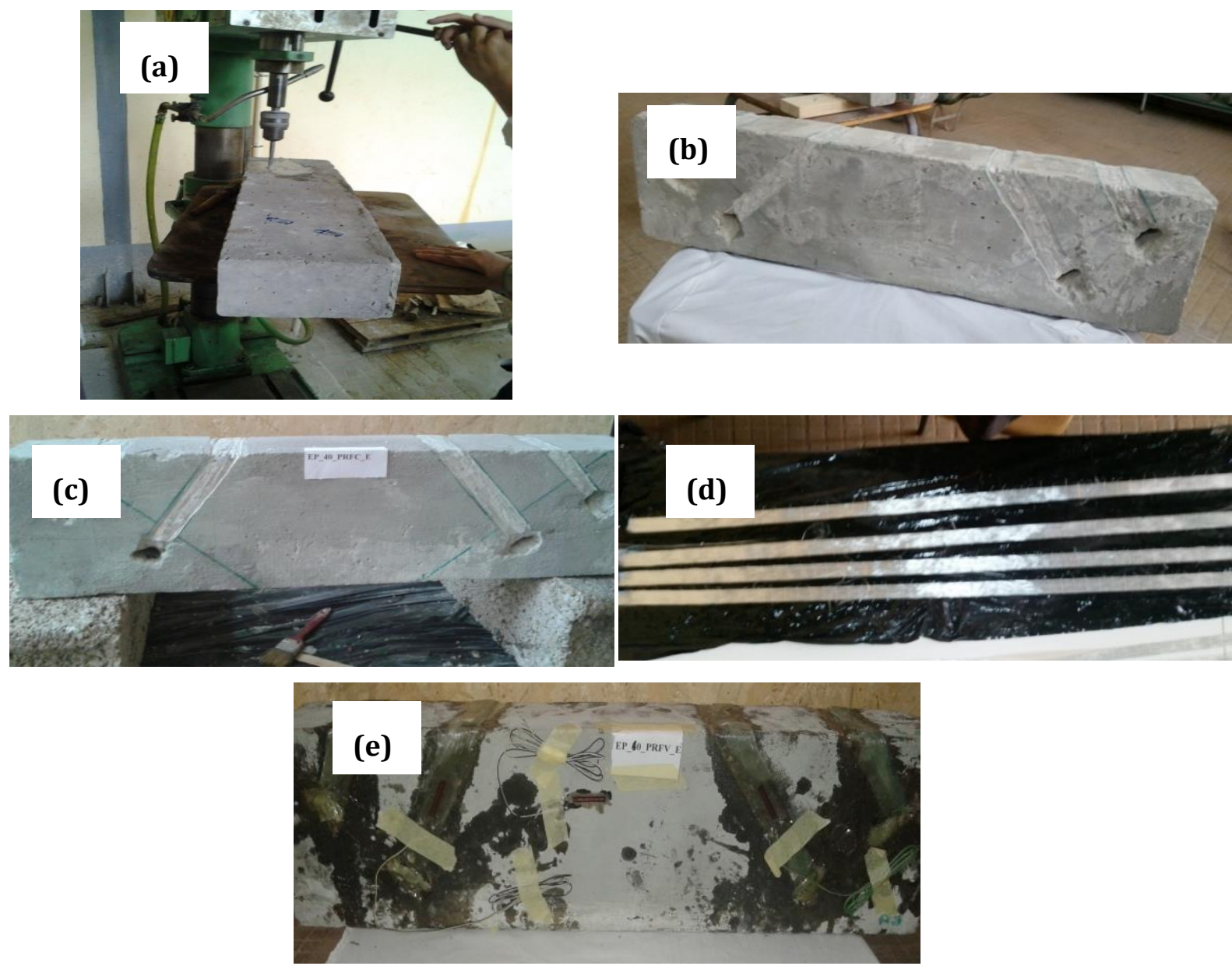

Fig 2. Repair of the beam (a) drilling of the holes (b) grooving (c) mortar reparation (d) cut of the unidirectional fabric (e) repair of the beam using SCR technique. 
The tests were carried out in a bending machine (Controls) in the architecture laboratory of the University of Guelma. The frame of this machine is equipped with a load cell of $100 \mathrm{kN}$ (Figure 3). The vertical displacement was measured, in the middle section, using an LVDT sensor with a maximum stroke of $100 \mathrm{~mm}$. The strains were measured using 3 strain gauges, where two are glued at the external surface of the composite bands and the third one in the tensile face in the middle of the beam (Figure 2e).

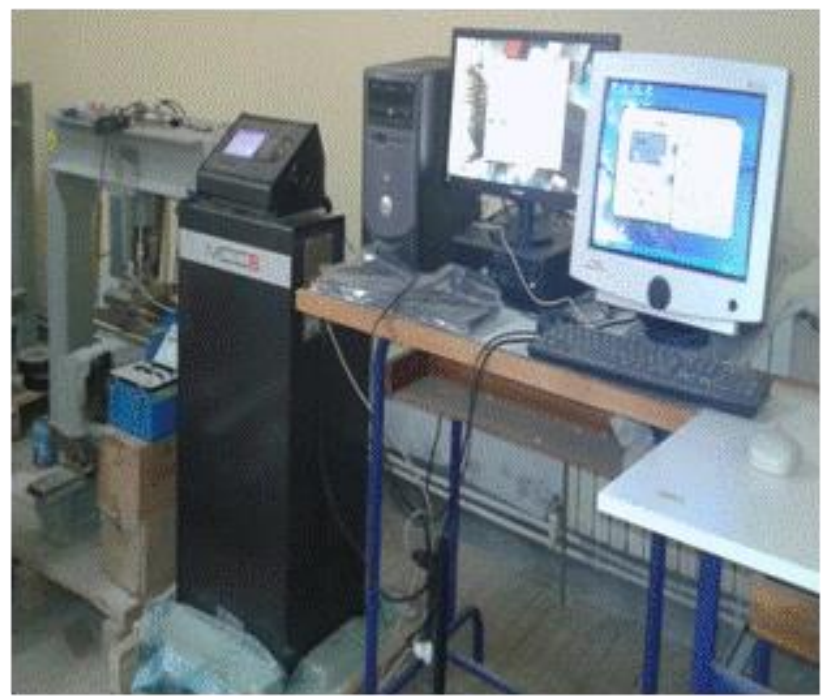

Fig 3. Machine test.

\section{Results and discussion}

\subsection{Global behavior}

The stress/displacement curves versus the loading, of the control beam and the beam preloaded at $65 \%$ and then repaired by the GFRP composite using SCR technique are represented in Figure 4. The curves obtained show that, after the discharges (at zero loads), the presence of a permanent displacement due to inelastic behavior and therefore the existence of residual arrows which can be interpreted as an irreversibility due to the cracking of the concrete. These results are in agreement with the ones obtained by (Boussaha, 2008) and (Kreit, 2011).

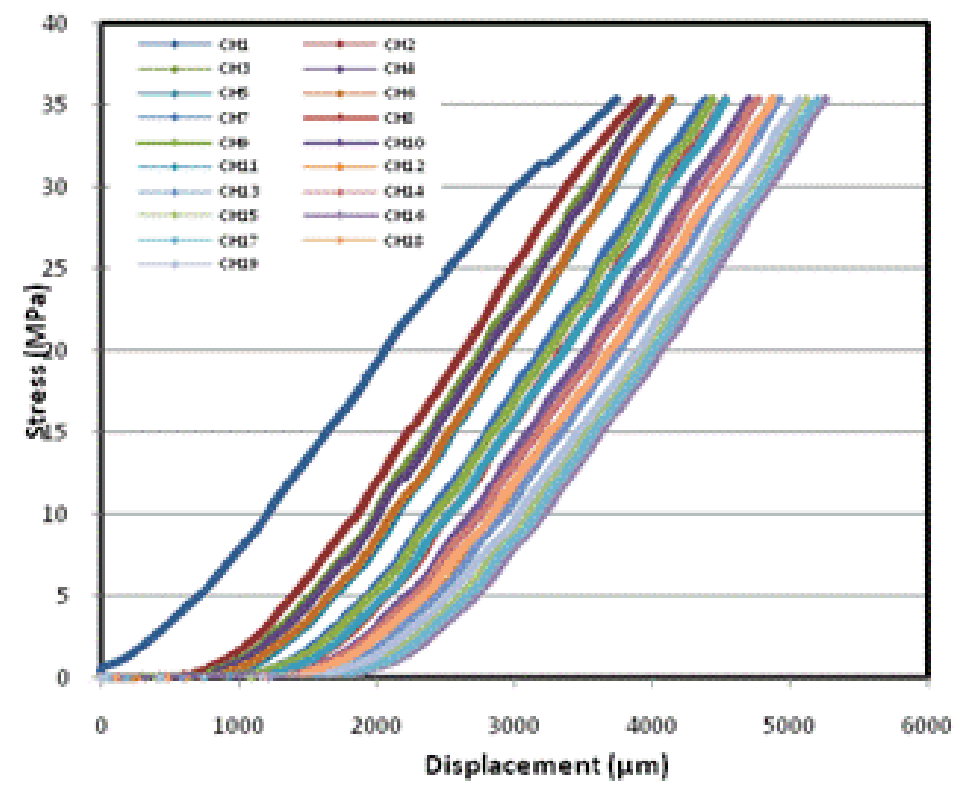

Fig 4. Stress/displacement of the beam EP_65\%_PRFV_E of the 19 cycles load/unload. 
The analysis of Figure 5 shows that the evolution of the stress/displacement of the control beam is very close to that obtained at the first cycle (1st cycle), whereas the curve of the $19^{\text {th }}$ cycle is distant from the previous one by approximately $1.64 \mathrm{~mm}$ (residual arrow) due to the plastification of the steel armature reinforcements of the tensile zone of the beam.

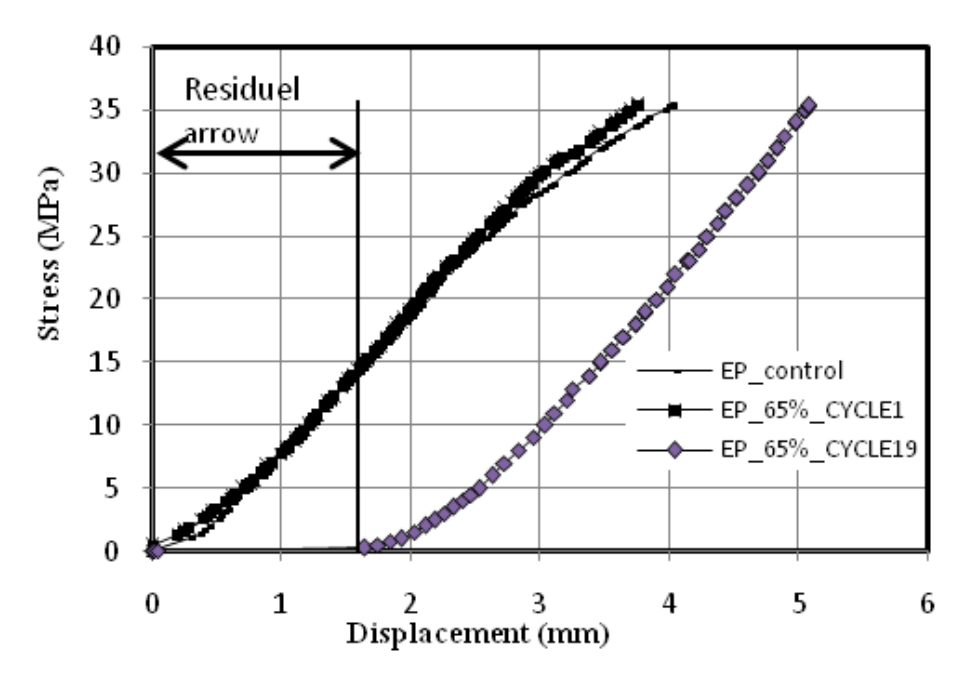

Fig 5. Evolution of the stress versus displacement of the control beam and EP_GFRP_65\%_Test 1 and Test 19.

The results obtained, under fatigue loading, show generally that the displacements versus the cycling (load/de-load) number of the repaired beam are higher compared to the control one. However, the maximum displacements reached during the first three cycles of the repaired beam are lower than that obtained for the control beam (Figure 6) and Table 1.

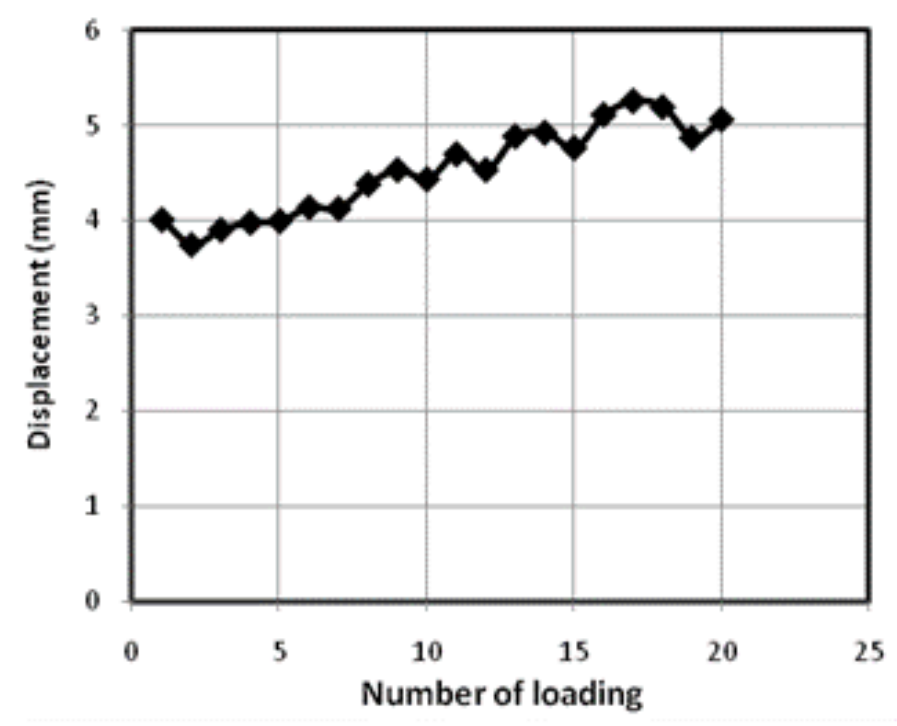

Fig 6. Evolution of the displacements versus the loading cycle numbers.

\subsection{Influence of the repair on the stiffness of the beams}

For the beam, preloaded and then repaired, bending stiffness was determined experimentally, which represents the slope of the linear part of the stress-displacement curve. The experimental results of the rigidities of the beams tested before and after the repair are presented in Figure 7.

A decrease of approximately $14.1 \%$ in the rigidity of the beam repaired with the GFRP is noticed for the 1st loading cycle compared to the control beam. However, in the second cycle, the 
stiffness increased by about $17 \%$ and then slow decrease is observed while remaining greater than the rigidity of the control beam even for the 19th cycle. These results are in good agreement with the work of Shahawy and Beitelman (1999).

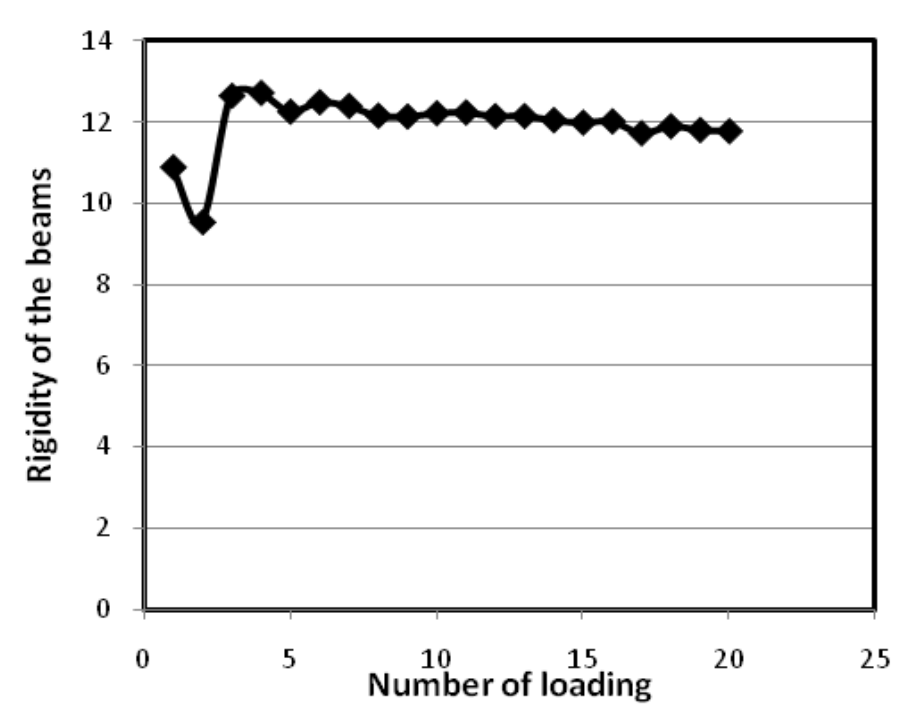

Fig 7. Stiffness of the beams during the cyclic fatigue tests.

\subsection{Local behavior}

The stress/strain curves for the first loading cycle, plotted using the strain gauges (g1, g3 and g4), which their locations are illustrated in Figure 10a, are shown in (Figures. 8 and 9). The strains are measured in the middle of the tensile zone of the concrete beam using g1, while g3 and $\mathrm{g} 4$ at the cracks. Table 1 recapitulates the obtained results of the strains gauges obtained by (g1, g3 and g4), displacements and rigidities of the control beam and the repaired one for the $19^{\text {th }}$ tests.

Table 1. Obtained strains using strain gauges (g1, g2 and g3), displacements and rigidities of the control beam and the repaired one for the $19^{\text {th }}$ tests.

\begin{tabular}{|l|l|l|l|l|l|}
\hline $\mathrm{N}^{\circ}$ of loading & $\begin{array}{l}\text { Strains } \\
\mathrm{g} 1(\mu \mathrm{m})\end{array}$ & $\begin{array}{l}\text { Strains } \\
\mathrm{g} 3(\mu \mathrm{m})\end{array}$ & $\begin{array}{l}\text { Strains } \\
\mathrm{g} 4(\mu \mathrm{m})\end{array}$ & $\begin{array}{l}\text { Displacements } \\
(\mathrm{mm})\end{array}$ & Rigidity \\
\hline \hline Control beam & 385 & 3566 & 132 & 4.01 & 10,9 \\
\hline Cycle 1 & 271 & 2553 & 2195 & 3.75 & 9,55 \\
\hline Cycle 2 & 353 & 2412 & 2742 & 3.91 & 12,66 \\
\hline Cycle 3 & 676 & 2303 & 1786 & 3.98 & 12,73 \\
\hline Cycle 4 & 736 & 2268 & 1792 & 4.00 & 12,27 \\
\hline Cycle 5 & 798 & 2228 & 1785 & 4.15 & 12,5 \\
\hline Cycle 6 & 823 & 2210 & 1802 & 4.13 & 12,41 \\
\hline Cycle 7 & 840 & 2156 & 1809 & 4.39 & 12,17 \\
\hline Cycle 8 & 865 & 2122 & 1812 & 4.54 & 12,15 \\
\hline Cycle 9 & 854 & 2119 & 1896 & 4.44 & 12,23 \\
\hline Cycle 10 & 888 & --- & --- & 4.71 & 12,25 \\
\hline Cycle 11 & 884 & 2107 & 1828 & 4.54 & 12,16 \\
\hline Cycle 12 & 863 & 2074 & 1813 & 4.89 & 12,16 \\
\hline Cycle 13 & 896 & 2092 & 1798 & 4.93 & 12,06 \\
\hline Cycle 14 & 891 & 2118 & 181 & 4.77 & 12 \\
\hline Cycle 15 & 893 & 2117 & 1790 & 5.12 & 12,03 \\
\hline Cycle 16 & 882 & 2119 & 1781 & 5.27 & 11,74 \\
\hline Cycle 17 & 866 & 2091 & 1784 & 5.2 & 11,91 \\
\hline Cycle 18 & 862 & 2134 & 1796 & 4.88 & 11,82 \\
\hline Cycle 19 & 864 & 2135 & 1766 & 5.07 & 11,79 \\
\hline
\end{tabular}


Figure 8 and Table 1 show the strains increases for the strain gauge (g1) from the $3^{\text {rd }}$ cycle compared to the control beam, ie an increase of $1237 \%$ for the $19^{\text {th }}$ cycle.

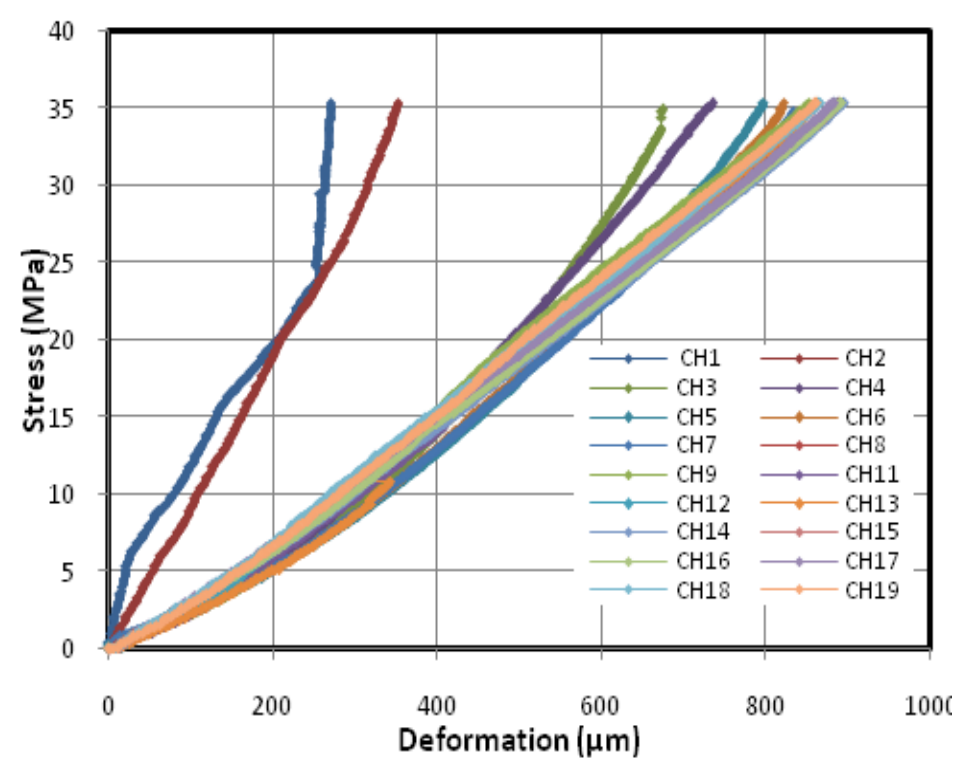

Fig 8. Stress/Strains obtained by strain gauge (g1) versus the cyclic loadings.

It should also be noted that the recorded strains of the composite with the strain gauge $\mathrm{g} 3 \mathrm{for}$ the repaired beam have decreased for all cycles. The strains obtained for the control beam and the repaired one after the $19^{\text {th }}$ cycle are respectively 3566 and $2135 \mu \mathrm{m}$, i.e. a decrease of $67 \%$ is noticed. While, increases for all loadings are recorded by the strain gauge (g4), ie approximately $1238 \%$ for the $19^{\text {th }}$ cycle (Figure 9 , Table 1 ).

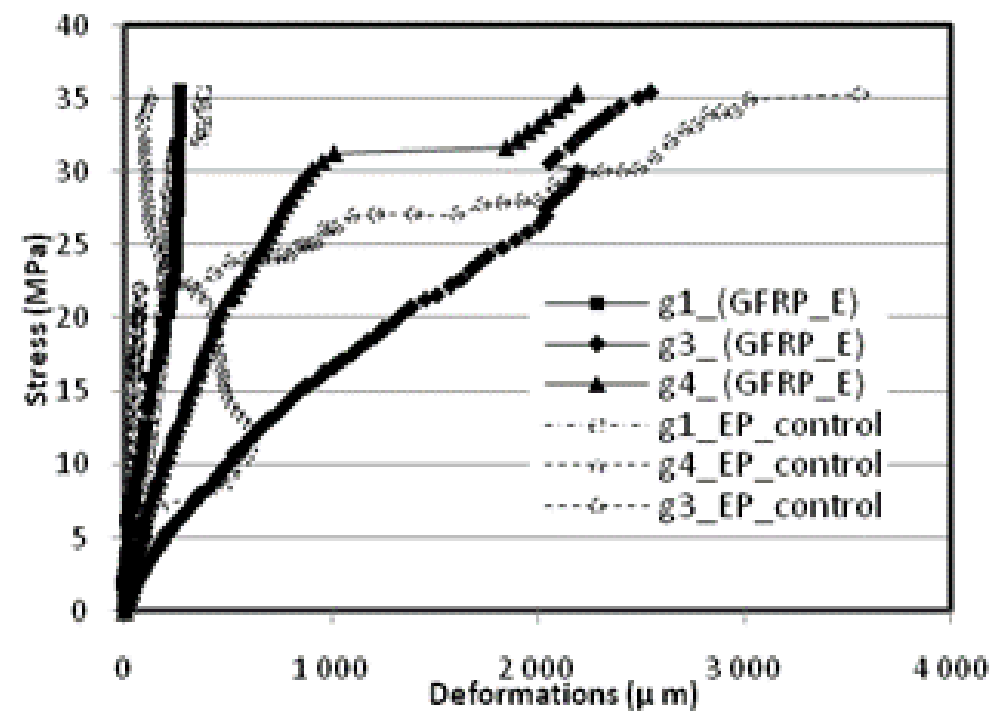

Fig 9. Stress/Strain (g1) for $1^{\text {st }}$ loading cycle of the beam (GFRP_65\%_E) and the control beam.

\subsection{Fissuration}

Figure 10a illustrates that the control beam subjected to 4-point bending has undergone a shear rupture, taking into account the type of cracking. The diagonal cracks were born on the lower supports and propagated towards the points of application of the upper load. 
Whereas the beam (EP_65\% _E) was repaired by GFRP, under a load of fatigue in the service state, the rupture was not yet reached even after 19 loadings thus showing the effectiveness of the repair adopted in this work (Figure 10b). Moreover, no peeling of the composite was detected during the tests and the beam passed the fatigue test successfully. The ductile failure mode has not been distinguished for beams repaired under fatigue loading for a service level; this will be reached in static.
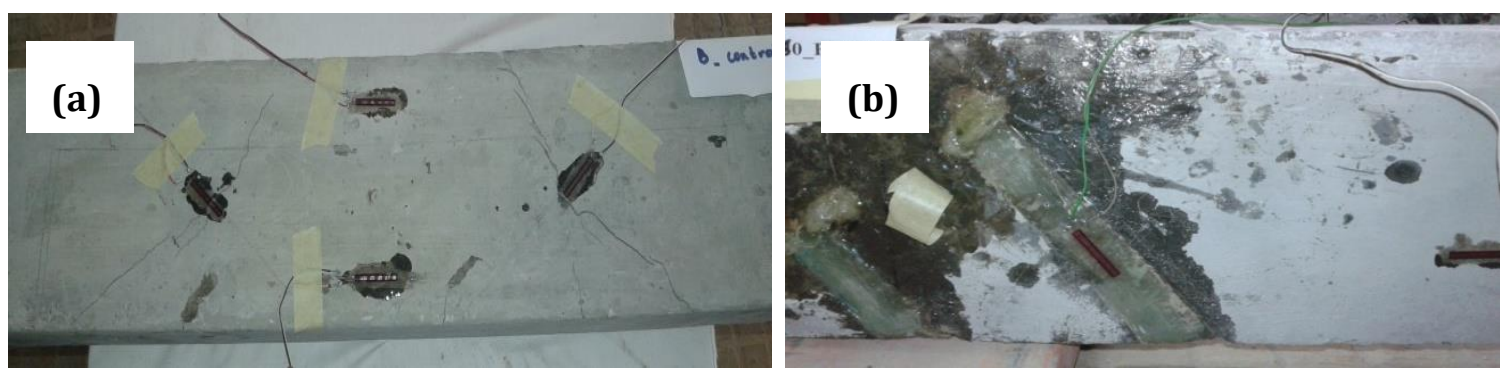

Fig 10. Failure modes

a) Control beam b) Beam preloaded at $60 \%$ then repaired by GFRP.

\section{Conclusions}

In this study, it was shown that the repair of beams using SCR technique exhibited good fatigue behavior. The mode of failure of the repaired beam has not yet been reached even for $19^{\text {th }}$ loading cycles. This result is very encouraging and must be confirmed by other tests in the future work. It is worth noticing that the presence of the composite in the shear zone not only reduced the potential crack propagation during fatigue cycles, but also stiffened the beams. Therefore, this technique has a very good resistance to fatigue loading.

\section{Acknowledgments}

The authors would like to acknowledge Mr BOUDJEHEM H from the Architecture laboratory of University of Guelma having to facilitate the access to the experimental machine.

\section{References}

Arduini, M., Nanni, A. (1997). Behavior of precracked RC beams strengthened with carbon, FRP sheets. ASCE Journal of Composites for Construction, 63-70.

Barnes, R. A., Mays G. C. (1999), Fatigue performance of concrete beams strengthened with CFRP plates, ASCE, Journal of composites for construction, $63-72$.

Boumaaza, M., Bezazi, A., Bouchelaghem, H., Benzennache, N., Amziane, S. and Scarpa. F. (2017). Behavior of pre-cracked deep beams with composite materials repairs, Techno Press, Structural Engineering and Mechanics 61(4), 575-583.

Boussaha, F. (2008). Comportement en fatigue des poutres en béton armé renforcées en cisaillement à l'aide de matériaux composites avancés. Thèse PhD, École de technologie supérieure, Montréal, Canada., 144.

Choi Y. W., Lee H. K., Chu S. B., Cheong S. H, and Jung, W. Y. (2012). Shear Behavior and Performance of Deep Beams Made with Self-Compacting Concrete. International Journal of Concrete Structures and Materials, 6 (2), 65-78.

De Lorenzis, L., Teng, J. G. (2007). Near-surface mounted FRP reinforcement: An emerging technique for strengthening structures. Composites: Part B, 38, 119-143.

Dong, J., Wang, Q., Guan, Z. (2013). Structural behavior of RC beams with external flexural and flexuralshear strengthening by FRP sheets, Composites: Part B, 44, 604-612.

Kreit, A., Mahmoud, F., Castel, A., François, A. (2011). Repairing corroded RC beam with near-surface mounted CFRP rods. Materials and Structures 44, 1205-1217. 
Masoud S., Soudki k., Topper T. (2001), CFRP-strengthened and corroded RC beams under monotonic and fatigue loads, ASCE Journal of composites for construction, pp.228 - 236.

Meier, U., Deuring, M., Meier, H., and Schwegler, G. (1992). Strengthening of structures with CFRP laminates: Research and applications in Switzerland. Advanced Compos. Mat. in Bridges and Struct., K. W. Neale and P. Labossiere, eds. Canadian Society for Civil Engineers, Montreal.

Papakonstantinou, C. G. (2000). Fatigue performance of reinforced concrete beams strengthened with glass fiber reinforced polymer composite sheets." MS thesis, University of South Carolina, Columbia, S.C.

Shahawy M., Beitelman T.E. (1999). Fatigue performance of RC beams strengthened with CFRP Laminates, proceedings of 1st CDDC international conference on durability of fiber reinforced polymer composite for construction, Sherbrook, August, 169-178.

Teo, W., Hing, K.L.M., and Liew, M.S. (2017). Interaction between Internal Shear Reinforcement and External FRP Systems of RC Beams: Experimental Study. The Open Civil Engineering Journal, 11, 143-152.

Wu, Z.Y. (2004). Etude expérimentale du comportement des Poutres courtes en béton armé pré-fissurées et Renforcées par matériaux composite sous Chargement statique et de fatigue. Thèse LCPC Paris, novembre. 